\title{
Comparison of ZnS Film Growth on Glass and CIGS Substrates via Hydrazine-assisted Chemical Bath Deposition for Solar Cell Application
}

\author{
Received November 15, 2019; accepted December 6, 2019
}

\section{Jeha Kim*}

Department of Energy Convergence, Cheongju University, Cheongju 28403, Republic of Korea

*Corresponding author E-mail: jeha@cju.ac.kr

\begin{abstract}
We investigate the effect of hydrazine on the growth and physical characteristics of $\mathrm{ZnS}$ thin films deposited on both soda-lime glass (SLG) and copper indium gallium selenide (CIGS)/Mo/SLG substrates as a function of the relative molar ratio of hydrazine to ammonia reagent, $r_{\mathrm{c}}$, for various deposition times $t_{\mathrm{d}}$. As $r_{\mathrm{c}}$ is varied from 0 to 0.56 , all the ZnS films on SLG (thickness of $d \sim 38 \mathrm{~nm}$ ) with hydrazine exhibit an amorphous structure, $[\mathrm{S} / \mathrm{Zn}]$ composition of $\sim 0.65$, and direct energy bandgap of $E_{\mathrm{g}}=3.54-3.75 \mathrm{eV}$. To compare the difference in device quality corresponding to the two types of substrates, we fabricate CIGS solar cells using ZnS buffers grown under conditions of $r_{\mathrm{c}}=0.28,0.42$ for $t_{\mathrm{d}}=30$ $\min , 15 \mathrm{~min}$ and without hydrazine with $r_{\mathrm{c}}=0.0$ and $t_{\mathrm{d}}=90 \mathrm{~min}$. The sample obtained with the ZnS buffer under conditions of $r_{\mathrm{c}}=0.28, t_{\mathrm{d}}=30$ min exhibits the best solar cell performance of $\eta=12.03 \%$. Our results prove that using hydrazine for ZnS buffer layer preparation via chemical bath deposition can significantly enhance the film quality for CIGS solar-cell fabrication.
\end{abstract}

Keywords: ZnS film, Hydrazine, Chemical bath deposition, Soda-lime glass, CIGS solar cell

\section{Introduction}

Chemical bath deposition (CBD) is currently the most commonly used simple, low-cost approach for fabricating large-area semiconductor thin films for application to solar cells [1]. In particular, CdS and $\mathrm{ZnS}$ thin films form the most commonly used n-type buffer layers in the fabrication of copper indium gallium selenide (CIGS) [2,3], $\mathrm{Cu}_{2} \mathrm{ZnSnS}_{4}$ [4], and CdTe [5] solar-cell devices. Unlike physical vapor deposition methods such as sputtering and e-beam evaporation, CBD involves the deposition of layers from an alkaline mixture solution of metal ions and a chalcogenide source with an appropriate complexing agent. Thus, it is crucial to optimize CBD parameters such as the precursor ratio, $\mathrm{pH}[6,7]$, and bath temperature [8] for preparing high-quality thin films.

In the CBD process, the relation between the complexing agent and the film growth rate depends on whether the reaction path chosen is heterogeneous or homogeneous precipitation route [9]. CBD-ZnS thin films are preferred to CBD-CdS thin films because of the nontoxicity of the $\mathrm{CBD}-\mathrm{ZnS}$ process and the improved light transmission of the resulting films in the wavelength range of 300-500 $\mathrm{nm}$ [10]. However, CBD-ZnS films require a longer deposition time, which is a drawback when compared with CBD-CdS films. This increased deposition time can be attributed to hydroxyl adulteration and poor control of the complexing agent with regard to the release of metal ions in the solution [11]. In this context, the use of thioacetamide (TAA) with ammonia in association with nitrilotriacetic acid trisodium salt $\left(\mathrm{Na}_{3} \mathrm{NTA}\right)$ has been reported to improve the CBD- $\mathrm{ZnS}$ growth rate [10].

Meanwhile, it has been reported that the CBD-ZnS thin-film quality can be improved when a second ligand (hydrazine, triethanolamine (TEA), ethanolamine) is present $[9,12,13]$. Among these ligands, hydrazine $\left(\mathrm{N}_{2} \mathrm{H}_{4}\right)$, as a potential reagent during $\mathrm{ZnS}$ deposition, can act as a bridging ligand to reduce the free-metal-ion concentration in the solution. This in turn can increase the deposition rate of $\mathrm{ZnS}$ along with the formation of a smooth and homogeneous layer on the substrates $[14,15]$. In this regard, previous studies have reported that the use of hydrazine in the CBD process can enhance the growth rate of $\mathrm{ZnS}$ thin films by a factor of nearly 6 [16].

Against this background, here we study and compare the effects of hydrazine on the growth and structural characteristics of $\mathrm{ZnS}$ thin films deposited on both soda-lime glass (SLG) and CIGS/Mo/SLG substrates as functions of the relative ratio of hydrazine to ammonia and the deposition time of the CBD process. Furthermore, the $\mathrm{ZnS}$ films fabricated with and without hydrazine are compared for solarcell performance via the fabrication of CIGS solar cells.

\section{Experimental method}

We used the standard CBD method [16] to prepare ZnS films deposited both on SLG and CIGS/Mo/SLG substrates with dimensions of $25 \times 25 \times 1.1 \mathrm{~mm}$. Prior to deposition, the SLG substrates were sequentially ultrasonically cleaned with acetone, ethanol, and deionized (DI) water for 10 min followed by drying with $\mathrm{N}_{2}$ gas. The metal ion and sulfur ion precursors used in the reaction bath included 
$50 \mathrm{ml}$ zinc sulfate heptahydrate $(0.019 \mathrm{M})$ and $50 \mathrm{ml}$ thiourea $(0.17$ $\mathrm{M})$. The complexing agents employed as the primary and secondary base ligands were ammonia $\left(\mathrm{NH}_{3}\right)$ and hydrazine $\left(\mathrm{N}_{2} \mathrm{H}_{4}\right)$, respectively. We prepared two sets of samples using 1) only ammonia and 2) hydrazine along with ammonia. We varied the molar concentration ratio, $r_{\mathrm{c}}$, of hydrazine by varying its volume relative to ammonia (50 $\mathrm{ml}$ ), while the remaining bath conditions were maintained constant; the ratio was varied as $r_{\mathrm{c}}=0\left(\right.$ no $\left.\mathrm{N}_{2} \mathrm{H}_{4}\right), 0.14\left(5 \mathrm{ml} \mathrm{N}_{2} \mathrm{H}_{4}\right), 0.28(10 \mathrm{ml}$ $\left.\mathrm{N}_{2} \mathrm{H}_{4}\right), 0.42\left(15 \mathrm{ml} \mathrm{N}_{2} \mathrm{H}_{4}\right)$, and $\left(20 \mathrm{ml} \mathrm{N}_{2} \mathrm{H}_{4}\right)$. The details of the reagent chemical conditions can be found elsewhere [16]. The SLG and CIGS/Mo/SLG substrates were inserted into the solution to realize various deposition thicknesses for the desired time intervals. Subsequently, the coated films were rinsed out in running DI water followed by drying with $\mathrm{N}_{2}$ gas and baked at $200{ }^{\circ} \mathrm{C}$ for $10 \mathrm{~min}$.

The crystallographic analysis of the $\mathrm{ZnS}$ films was performed with use of high-angle and low-angle $\left(\theta_{\text {inc }}=8^{\circ}\right)$ X-ray diffraction (XRD, Rigaku) by using CuKa radiation with $\lambda=0.154 \mathrm{~nm}$. The surface morphology of the films was investigated by means of a fieldemission scanning electron microscope (FE-SEM, JSM-6701F, JEOL) with applied voltages of up to $K_{\mathrm{e}}=15 \mathrm{keV}$. The elemental composition of the as-grown films was recorded by means of an energy-dispersive spectroscopy (EDS) device attached to the FE-SEM. Atomic-scale images of ZnS were obtained to confirm the crystalline growth using high-resolution transmission electron microscopy (HR-TEM). The optical transmittance of the films was measured with the use of an ultraviolet-visible-near-infrared (UV-Vis-NIR) spectrophotometer (Hitachi, U-4100) in the wavelength range of 300-1300 nm. To investigate the quality of the CBD-ZnS films, we fabricated CIGS solar cells with the device structure of $\mathrm{Al} / \mathrm{Ni} / \mathrm{ITO} / \mathrm{i}-\mathrm{ZnO} / \mathrm{ZnS}-\mathrm{CIGS} / \mathrm{Mo} / \mathrm{SLG}$ [17]. The current-voltage $(J-V)$ characteristics of the CIGS solar cell devices were measured with the use of a $J-V$ source meter (Keithley 2400) under a global AM 1.5 spectrum at room temperature.

\section{Results and discussion}

In the beginning of $\mathrm{CBD}$ process, the $\mathrm{pH}$ value of the solution bath dropped rapidly to 9.7 from over 10.5 for the first $10 \mathrm{~min}$ and it subsequently linearly decreased to 9.0 in the interval of $10 \mathrm{~min} \leq t_{\mathrm{d}} \leq$ $120 \mathrm{~min}$ for all values of $r_{\mathrm{c}}$. This rapid drop in the $\mathrm{pH}$ was attributed to a nucleation stage that led to the acceleration of the hydrolysis of thiourea and/or the formation of an intermediate phase of $\mathrm{Zn}(\mathrm{OH})_{2}$ $[9,11,15]$. Thus, all the CBD-ZnS films were prepared with deposition times of $t_{\mathrm{d}} \geq 10 \mathrm{~min}$ for stable grain growth. The slow and linear decrease in $\mathrm{pH}$, that is, the concentration of $\mathrm{OH}^{-}$ions, was attributed to the heterogeneous deposition of the stable $\mathrm{ZnS}$ thin film onto the SLG or CIGS substrates [18]. Here, we note that the decrease in $\mathrm{pH}$ was independent of the amount of hydrazine $r_{\mathrm{c}}$ in ammonia.

Figure 1 shows the in-plane SEM images of the $\mathrm{ZnS}$ thin films deposited on SLG substrates at $t_{\mathrm{d}}=30,60$, and 90 min with different relative hydrazine ratios of $r_{\mathrm{c}}=0.0,0.28$, and 0.56 . We note that the surface morphologies of all samples appear smooth and are composed of round grains of various sizes. It can also be observed that the grain growth of ZnS on SLG is strikingly different without $\left(r_{\mathrm{c}}=0.0\right)$ and with $\left(r_{\mathrm{c}} \neq 0.0\right)$ hydrazine. For all samples, the $\mathrm{ZnS}$ grains increase in size with increase in the deposition time $t_{\mathrm{d}}$ and relative hydrazine ratio $r_{c}$. In the sample prepared with only ammonia, several large grains agglomerated into islands with a height of $\sim 46 \mathrm{~nm}$, and as the deposition progressed, they coalesced to cover the entire surface. During

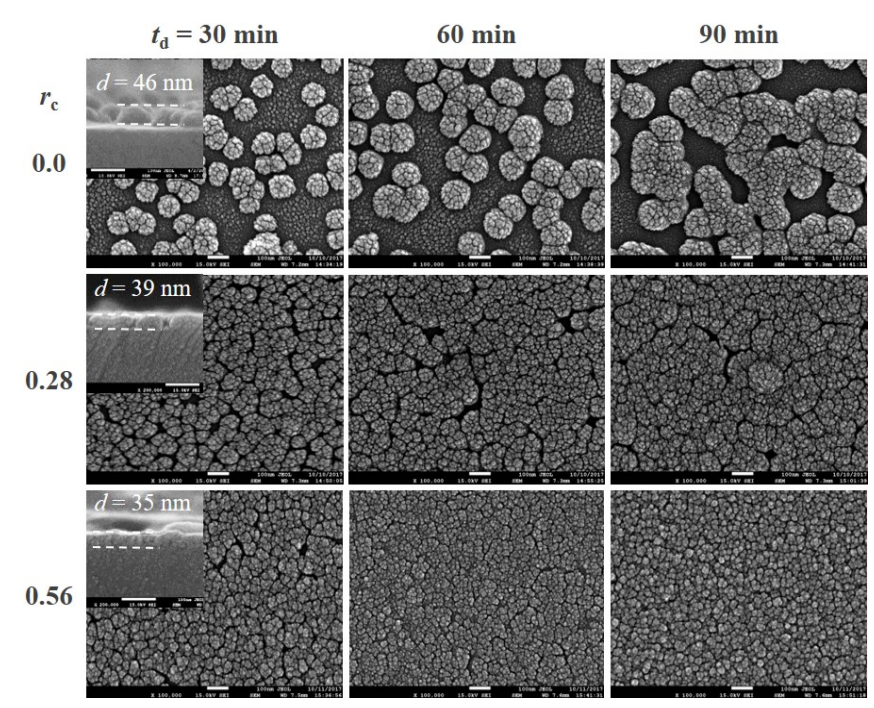

Figure 1. In-plane ZnS grain growth on soda-lime glass (SLG) as function of growth time $t_{\mathrm{d}}$ and molar ratio of hydrazine $r_{\mathrm{c}}$. The inset shows the cross-sectional image of the grains. The scale bar is $100 \mathrm{~nm}$.

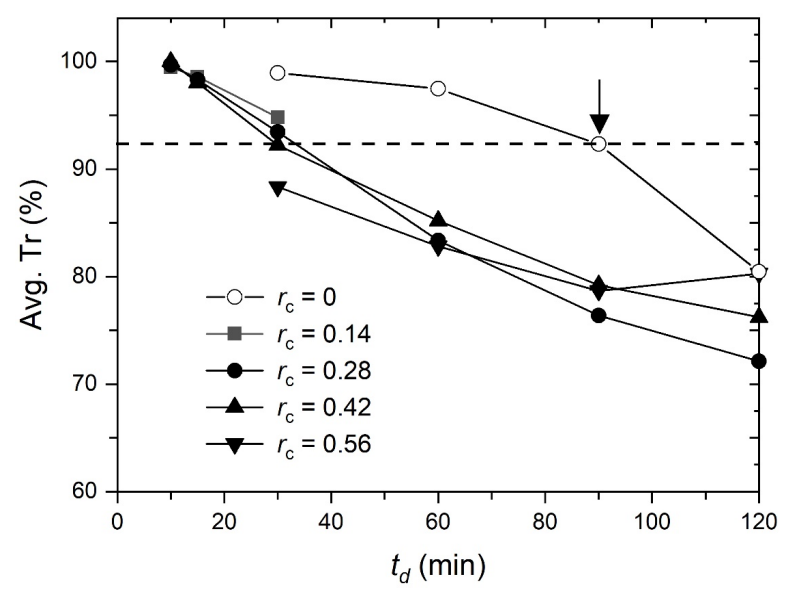

Figure 2. Average light transmission as function of deposition time $t_{\mathrm{d}}$. The open and closed symbols correspond to the molar ratio of hydrazine $r_{\mathrm{c}}=0$ and $r_{\mathrm{c}} \neq 0$, respectively. The average light transmission $(\mathrm{Tr})$ was considered for the wavelength window of $400-1100 \mathrm{~nm}$, and the dashed line indicates Avg. $\mathrm{Tr}=93 \%$ for comparison purposes.

the growth process, the grain height did not change noticeably.

In contrast, we also note that the oval-shaped grains reduce both in shape and height when prepared in the mixed solution of ammonia and hydrazine (Fig. 1). However, the surface coverage by the grains is significantly improved relative to the case of deposition without hydrazine. In the figure, we note that the $\mathrm{ZnS}$ layer prepared with $r_{\mathrm{c}}=$ 0.28 nearly completely covers the substrate even at $t_{\mathrm{d}}=30 \mathrm{~min}$; the film is densely packed in the plane. Moreover, at $r_{\mathrm{c}}=0.56$, the $\mathrm{ZnS}$ layer appears even more densely packed. In our study, the grain size tended to reduce with increase in $r_{\mathrm{c}}$ and $t_{\mathrm{d}}$ although the size variation was small; consequently, the $\mathrm{ZnS}$ film exhibited close packing with rounded grains.

Optical transmission through the ZnS thin films was measured using a UV-Vis-NIR spectrophotometer. Figure 2 plots the average light transmission (Avg. Tr) evaluated in the wavelength range of $\lambda=$ 


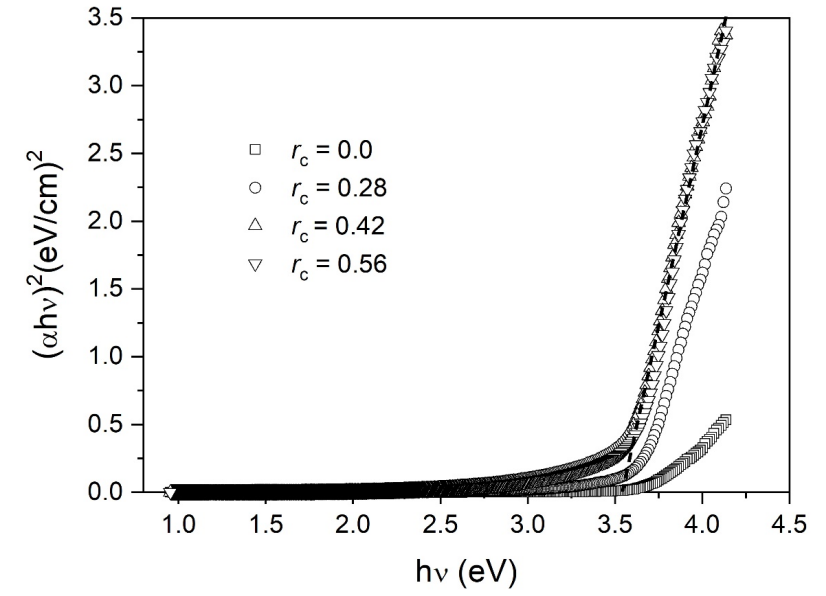

Figure 3. Tauc plots corresponding to $(\alpha h v)^{2}=C\left(h v-E_{g}\right)$ for $Z n S$ on soda-lime glass (SLG) substrate for different molar ratios of hydrazine $r_{c}$ prepared at deposition time $t_{d}=30 \mathrm{~min}$.

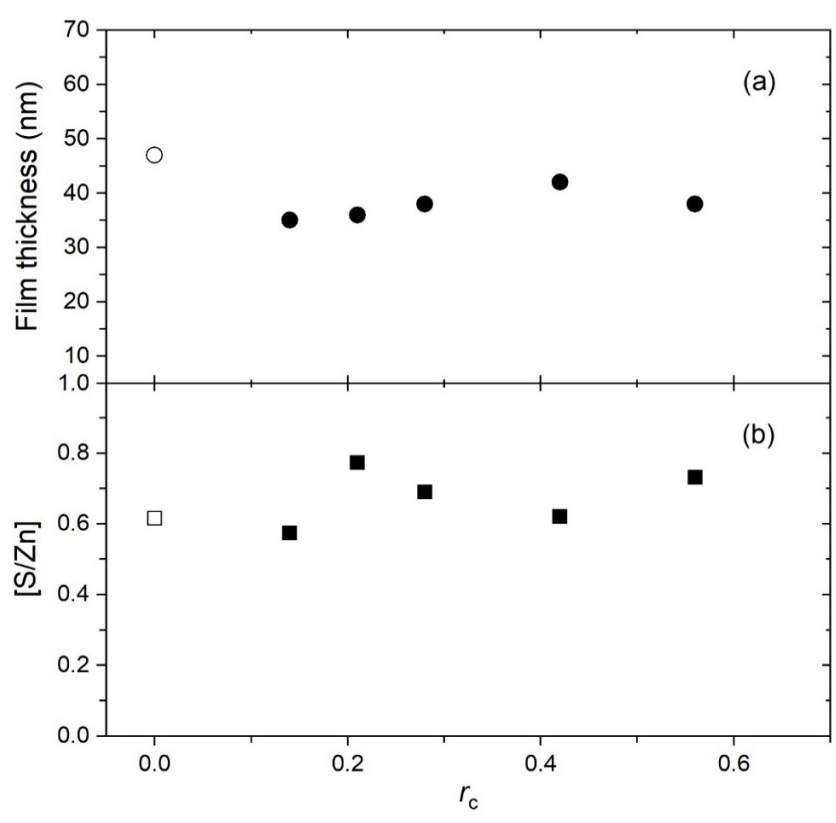

Figure 4. Film thickness (a) and composition ratio [S/Zn] (b) of ZnS films as functions of the molar ratio of hydrazine $r_{c}$ when deposited on soda-lime glass (SLG) for deposition time $t_{d}=30 \mathrm{~min}$. The average thickness $d \sim 35 \mathrm{~nm}$ and ratio $[\mathrm{S} / \mathrm{Zn}] \sim 0.67$.

400-1100 nm as a function of the deposition time $t_{\mathrm{d}}$. The Avg. Tr value decreases monotonically with $t_{\mathrm{d}}$ for all samples for $r_{\mathrm{c}} \neq 0$, while it behaves differently for the films with $r_{\mathrm{c}}=0$ (no hydrazine). The high transmission of the sample for $r_{\mathrm{c}}=0$ (no hydrazine) can be interpreted as the passage of a large amount of light through the film because of the poor surface coverage of $\mathrm{ZnS}$ film on the SLG substrate (Fig. 1). Keeping in mind that the optical absorption of a film is affected by the layer thickness, we note that the absorption of the $\mathrm{ZnS}$ film prepared under the conditions of $t_{\mathrm{d}}=90 \mathrm{~min}, r_{\mathrm{c}}=0$ with Avg. $\mathrm{Tr}$ $=93 \%$ (dashed line in Fig. 1) is identical to that of the film prepared at $t_{\mathrm{d}}=30$ min and $r_{\mathrm{c}} \neq 0$.

Next, we estimated the optical energy bandgap Eg of the ZnS films using the relation $(\alpha h v)^{2}=\mathrm{C}\left(h v-E_{\mathrm{g}}\right)$, where C denotes a con-
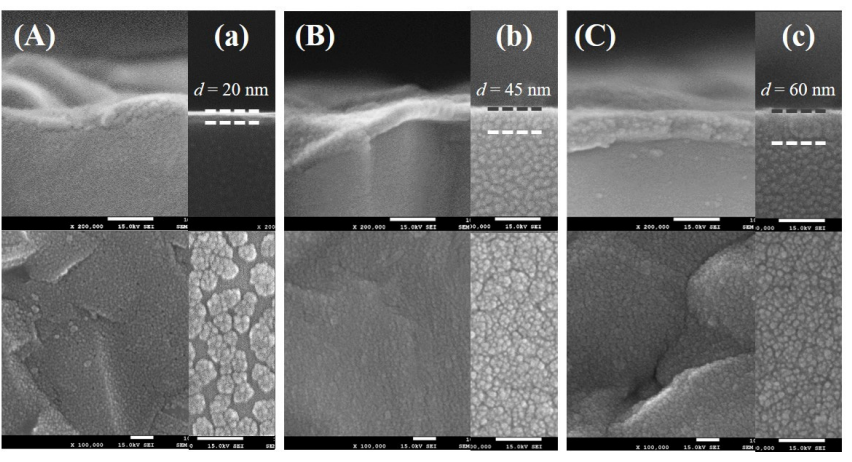

Figure 5. Cross-sectional (top) and surface morphology (bottom) images of ZnS films grown on copper indium gallium selenide (CIGS)/Mo/soda-lime glass (SLG) substrate for deposition time $t_{d}=(A) 10,(B) 30$, and (C) 60 min at molar hydrazine ratio $r_{c}$ $=0.28\left(10 \mathrm{ml}\right.$ of $\left.\mathrm{N}_{2} \mathrm{H}_{4}\right)$. The inset figures on the right in each panel show the corresponding images of $\mathrm{ZnS}$ grains grown on the SLG substrate. The scale bar is $100 \mathrm{~nm}$.

stant and $h v$ the incident photon energy in the Tauc plot, as shown in Fig. 3. We note that Eg is independent of the chemical solution associated with hydrazine; its value lies between 3.54 and $3.75 \mathrm{eV}$, which is slightly larger than the direct bandgap energy $(3.54 \mathrm{eV})$ of bulk $\mathrm{ZnS}$ with its cubic structure [16].

Figure 4 shows the plots of (a) the $\mathrm{ZnS}$ film thickness deposited for $t_{\mathrm{d}}=30 \mathrm{~min}$ and (b) the composition ratio [S/Zn] as functions of $r_{\mathrm{c}}$. The film thickness was obtained from the cross-sectional FE-SEM images. The highest film thickness of $\sim 47 \mathrm{~nm}$ is observed when $r_{\mathrm{c}}=0$, whereas the films grown with $r_{\mathrm{c}}>0$ exhibit a thickness $d \sim 38 \mathrm{~nm}$. As $r_{\mathrm{c}}$ increases, the film thickness $d$ slightly changes and saturates in the range of $d=30-50 \mathrm{~nm}$. The $\mathrm{ZnS}$ grains show no overgrowth on the layer formed earlier but exhibit close packing in the plane, which affords increased surface coverage with increase in both $r_{\mathrm{c}}$ and $t_{\mathrm{d}}$. On the other hand, the composition ratio of $[\mathrm{S} / \mathrm{Zn}]$ is $\sim 0.65$ in most samples, and the ratio exhibits a slight overall linear increase with increase in $r_{\mathrm{c}}$, as depicted in Fig. 4(b).

To study the growth characteristics of the $\mathrm{ZnS}$ grains on the CIGS/Mo/SLG substrate, we acquired high-resolution SEM images of the sample surfaces. Figure 5 shows SEM surface morphology of $\mathrm{ZnS}$ on CIGS/Mo/SLG grown at $t_{\mathrm{d}}=$ (A) 10 , (B) 30 , and (C) 60 min with hydrazine content of $r_{\mathrm{c}}=0.28\left(10 \mathrm{ml}\right.$ of $\left.\mathrm{N}_{2} \mathrm{H}_{4}\right)$. The inset image in each case represents the SEM image of ZnS on SLG under the corresponding growth conditions, that is, (A) for (a) and so on. It is noteworthy that the $\mathrm{ZnS}$ grain growth is strongly dependent on the choice of substrate: SLG or CIGS/Mo/SLG. That is, ZnS on CIGS/Mo/SLG for $t_{\mathrm{d}}=10$ min exhibits nearly complete surface coverage (Fig. 5(a)) with the formation of a thick layer, whereas ZnS on SLG exhibits incomplete surface coverage with a small layer thickness of $d=20 \mathrm{~nm}$. With increase in the deposition time $t_{\mathrm{d}}$, the $\mathrm{ZnS}$ surface appears increasingly densely packed, and complete surface coverage is achieved with uniform-sized grains. This evidences the fact that $\mathrm{ZnS}$ grain growth in the CBD process is strongly dependent on the substrate conditions. For the solar-cell application of $\mathrm{ZnS}$ buffer onto absorber layers, such as in CIGS, CdTe, and CZTS cells, the growth mechanism with hydrazine-added $\mathrm{ZnS}$ buffer can be more efficient than on SLG substrates.

Figure 6 depicts the XRD spectra of the $\mathrm{ZnS}$ films deposited on the SLG substrate at $r_{\mathrm{c}}=0,0.28$, and 0.56 for $t_{\mathrm{d}}=90,30$, and $15 \mathrm{~min}$, 


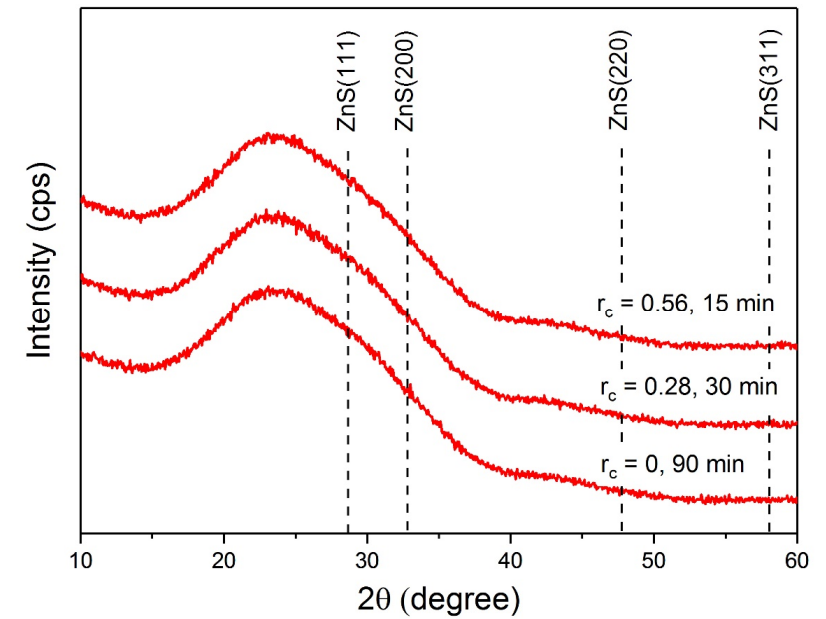

Figure 6. (Color online) Grazing-incidence X-ray diffraction (XRD) spectra acquired at $\theta_{\text {inc }}=8^{\circ}$ from ZnS films on soda-lime glass (SLG) substrate.

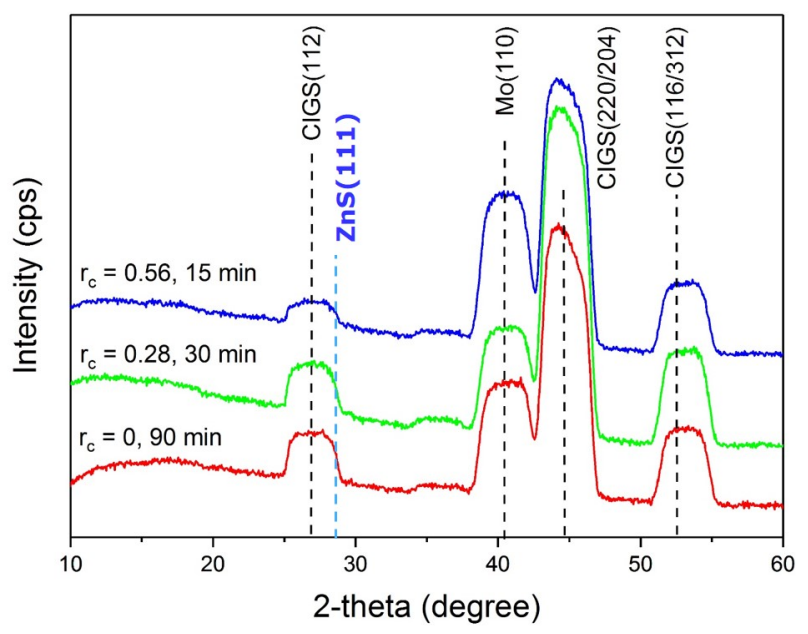

Figure 7. (Color online) Grazing-incidence X-ray diffraction (XRD) spectra acquired at $\theta_{\text {inc }}=8^{\circ}$ from ZnS films on copper indium gallium selenide (CIGS)/Mo/soda-lime glass (SLG) substrate.

respectively. A broad peak corresponding to amorphous $\mathrm{ZnS}$ at $2 \theta \sim$ $25^{\circ}$ can be observed for all the samples, which partly results from the small layer thickness in the range of $\sim 37-47 \mathrm{~nm}$. Even in the XRD experiment with the grazing-incidence scattering geometry of $\theta_{\text {inc }}=$ $8^{\circ}$, no indication of the grain growth in the $(111)^{\text {cubic }} /(002)^{\text {hex }}$ planes of $\mathrm{ZnS}$ at $2 \theta=29.5^{\circ}$ is observed for all the samples. In general, the $\mathrm{ZnS}$ films exhibited nearly identical amorphous structures for all the samples, and from the peaks, we could not discern whether their growth could be attributed to a cubic or hexagonal structure [18]. Furthermore, no crystalline growth of the ZnS layer was observed even in our X-ray diffraction experiments with the grazing-incidence scattering geometry, which was attributed to the small layer thickness of $d=37-47 \mathrm{~nm}$. Figure 7 displays the XRD pattern obtained from the $\mathrm{ZnS}$ films deposited on the CIGS/Mo/SLG substrate at $r_{\mathrm{c}}=0,0.28$, and 0.56 for $t_{\mathrm{d}}=90,30$, and $15 \mathrm{~min}$, respectively. As in the case of the ZnS films on the SLG substrate, we could not identify any X-ray scattering from $\mathrm{ZnS}$ on the CIGS/Mo/SLG substrate for the same

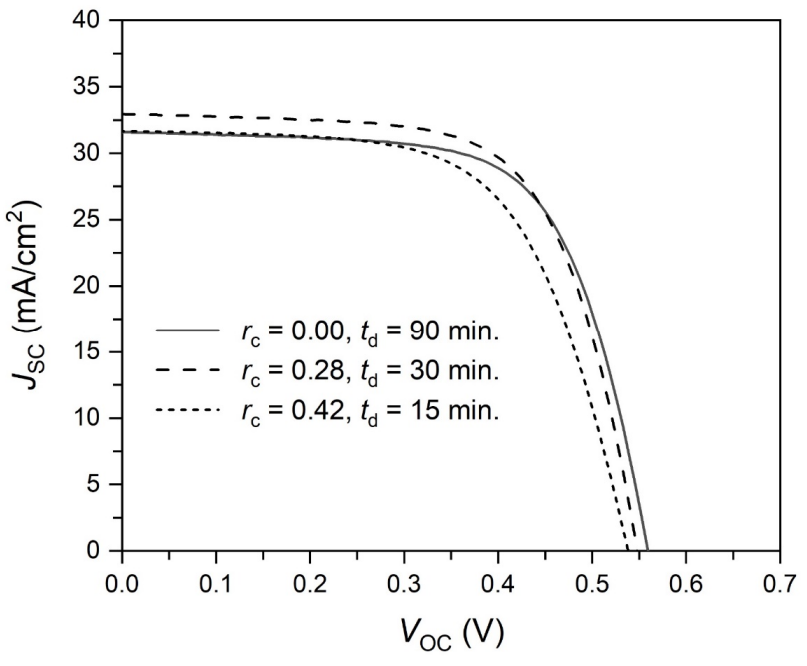

Figure 8. Current-voltage (J-V) characteristics of ZnS/copper indium gallium selenide (CIGS) solar cells as function of hydrazine ratio $r_{\mathrm{c}}$ and deposition time $t_{\mathrm{d}}$.

grazing-incidence scattering geometry of $\theta_{\text {inc }}=8^{\circ}$. Considering that the layer thickness of the underlying CIGS film is $d \sim 2.0 \mu \mathrm{m}$, there is little chance of observing any X-ray scattering from $\mathrm{ZnS}$ (111) with $d$ $=37-47 \mathrm{~nm}$, as indicated in Fig. 7. Regardless of CBD with and without hydrazine and on different substrates, all the sample $\mathrm{ZnS}$ films exhibited nearly identical amorphous structures, and from the peaks, it could not be discerned whether cubic or hexagonal structures were responsible for their growth.

Next, to investigate the effectiveness of hydrazine as an additive complex agent in conjunction with ammonia, we fabricated CIGS solar cells with various $\mathrm{ZnS}$ buffers, which showed similar optical qualities corresponding to Avg. $\operatorname{Tr}=93 \%$. With the optical quality of samples being maintained as in Fig. 2, we prepared $\mathrm{ZnS}$ buffer layers with hydrazine ratios of $r_{\mathrm{c}}=0.00,0.28$, and 0.42 for deposition times of $t_{\mathrm{d}}=90,30$, and $15 \mathrm{~min}$, respectively. Figure 8 shows the currentvoltage $(J-V)$ curves measured from the solar cells for various hydrazine ratios $r_{\mathrm{c}}$ and deposition times $t_{\mathrm{d}}$ [16]. The best solar cell performance, corresponding to an efficiency of $\eta=12.03 \%$, open-circuit voltage of $V_{o c}=0.549 \mathrm{~V}$, short-circuit current of $J_{\mathrm{sc}}=32.92 \mathrm{~mA} / \mathrm{cm}^{2}$, and fill factor $F F=66.7 \%$, is obtained from the sample with the $\mathrm{ZnS}$ buffer corresponding to $r_{\mathrm{c}}=0.28$ and $t_{\mathrm{d}}=30 \mathrm{~min}$. Although the solar parameters varied for the other samples, it is obvious that the solarcell quality mainly depends on the $r_{\mathrm{c}}$ value. Although $V_{\mathrm{oc}}$ is reduced slightly, the sample with $\mathrm{ZnS}$ obtained with $r_{\mathrm{c}}=0.42, t_{\mathrm{d}}=15 \mathrm{~min}$ exhibits nearly identical results with that obtained with $r_{\mathrm{c}}=0.28, t_{\mathrm{d}}=$ $30 \mathrm{~min}$ and that prepared with no hydrazine for $t_{\mathrm{d}}=90 \mathrm{~min}$. These results suggest that the use of hydrazine in conjunction with ammonia in $\mathrm{CBD}$ solution is beneficial in reducing the deposition time.

\section{Conclusion}

We investigated and compared the effect of hydrazine on the growth and physical characteristics of $\mathrm{ZnS}$ thin films deposited on both SLG and CIGS/Mo/SLG substrates as a function of the relative molar ratio of hydrazine, $r_{\mathrm{c}}$, with respect to ammonia reagent for various deposition times $t_{\mathrm{d}}$. As $r_{\mathrm{c}}$ was varied from 0 to 0.56 , all the $\mathrm{ZnS}$ films on SLG (with a thickness $d \sim 38 \mathrm{~nm}$ ) with hydrazine exhibited 
an amorphous structure, $[\mathrm{S} / \mathrm{Zn}]$ composition of $\sim 0.65$, and direct energy bandgap of $E_{\mathrm{g}}=3.54-3.75 \mathrm{eV}$. In addition, we were not able to observe crystalline growth of $\mathrm{ZnS}$ deposited on both sets of substrates. For comparison of the device quality corresponding to the two sets of substrates, we fabricated CIGS solar cells using $\mathrm{ZnS}$ buffers grown under conditions of $r_{\mathrm{c}}=0.28,0.42$ for $t_{\mathrm{d}}=30 \mathrm{~min}, 15 \mathrm{~min}$ and without hydrazine $\left(r_{\mathrm{c}}=0.0\right)$ for $t_{\mathrm{d}}=90 \mathrm{~min}$. The sample with the $\mathrm{ZnS}$ buffer corresponding to $r_{\mathrm{c}}=0.28, t_{\mathrm{d}}=30$ min exhibited the best solar cell performance of $\eta=12.03 \%$. Our results conclusively prove that using hydrazine for the $\mathrm{ZnS}$ buffer during CBD deposition is very effective in enhancing the film quality and reducing the deposition time for CIGS solar-cell fabrication.

\section{Acknowledgements}

This work was supported by a research grant from Cheongju University (2018.03.01 2020.02.28.)

\section{References}

[1] S. Shaji, L. V. Garcia, S. L. Loredo, B. Krishnan, J. A. Aguilar Martinez, T. K. Das Roy, and D. A. Avellaneda, Appl. Surf. Sci. 393, 369 (2017).

[2] S. Karki, P. K. Paul, G. Rajan, T. Ashrafee, K. Aryal, P. Pradhan, R. W. Collins, A. Rockett, T. J. Grassman, S. A. Ringel, A. R. Arehart, and S. Marsillac, IEEE J. Photovolt. 7, 665 (2016).

[3] W. J. Lee, H. J. Yu, J. H. Wi, D. H. Cho, W. S. Han, J. Yoo, Y. Yi, J. H. Song, and Y. D. Chung, ACS Appl. Mater. Interfaces 8, 22151 (2016).

[4] J. Y. Park, R. B. V. Chalapathy, A. C. Lokhande, C. W. Hong, and
J. H. Kim, J. Alloys Compd. 695, 2652 (2017).

[5] J. Han, C. Spanheimer, G. Haindl, G. Fu, V. Krishnakumar, J. Schaffner, C. Fan, K. Zhao, A. Klein, and W. Jaegermann, Sol. Energy Mater. Sol. Cells 95, 816 (2011).

[6] H. Ke, S. Duo, T. Liu, Q. Sun, C. Ruan, X. Fei, J. Tan, and S. Zhan, Mater. Sci. Semicond. Process. 18, 28 (2014).

[7] T. Ben Nasr, N. Kamoun, M. Kanzari, and R. Bennaceur, Thin Solid Films 500, 4 (2006).

[8] G. L. Agawane, S. W. Shin, M. S. Kim, M. P. Suryawanshi, K. V. Gurav, A. V. Moholkar, J. Y. Lee, J. H. Yun, P. S. Patil, and J. H. Kim, Curr. Appl. Phys. 13, 850 (2013).

[9] J. Liu, A. Wei, and Y. Zhao, J. Alloys Compd. 588, 228 (2014).

[10] D. Hariskos, R. Menner, P. Jackson, S. Paetel, W. Witte, W. Wischmann, M. Powalla, L. Bürkert, T. Kolb, M. Oertel, B. Dimmler, and B. Fuchs, Prog. Photovoltaics Res. Appl. 20, 534 (2012).

[11] T. Iwashita and S. Ando, Thin Solid Films 520, 7076 (2012).

[12] K. Deepa, K. C. Preetha, K. V. Murali, A. C. Dhanya, A. J. Ragina, and T. L. Remadevi, Optik (Stuttg). 125, 5727 (2014).

[13] P. O'Brien, D. J. Otway, and D. Smyth-Boyle, Thin Solid Films 361 $-362,17$ (2000).

[14] F. Long, W. M. Wang, Z. Cui, L. Z. Fan, Z. Zou, and T. Jia, Chem. Phys. Lett. 462, 84 (2008).

[15] J. M. Doña and J. Herrero, J. Electrochem. Soc. 141, 205 (1994).

[16] J. Kim, C. R. Lee, V. K. Arepalli, S. J. Kim, W. J. Lee, and Y. D. Chung, Mater. Sci. Semicond. Process. in press.

[17] D. H. Cho, K. S. Lee, Y. D. Chung, J. H. Kim, S. J. Park, and J. Kim, Appl. Phys. Lett. 101, 023901 (2012).

[18] T. Liu, H. Ke, H. Zhang, S. Duo, Q. Sun, X. Fei, G. Zhou, H. Liu, and L. Fan, Mater. Sci. Semicond. Process. 26, 301 (2014). 